\title{
Wholemeal versus wholegrain breads: proportion of whole or cracked grain and the glycaemic response
}

\author{
David J A Jenkins, Virginia Wesson, Thomas M S Wolever, Alexandra L Jenkins, Janet Kalmusky, \\ Silvia Guidici, Adel Csima, Robert G Josse, Gerald S Wong
}

Department of Nutritional Sciences, Faculty of Medicine, University of Toronto, Toronto, Ontario, Canada M5S 1 A8 David J A Jenkins, DM, professsor

Thomas M S Wolever, BM, assistant professor

Alexandra L Jenkins, RPDT,

Janet Kalmusky, RPDT, research dietitian dietitian

Virginia Wesson, MSC, medical student

\section{Department of}

Biostatistics, Faculty of Medicine, University of

Toronto

Adel Csima, PHD

\section{Division of Endocrinology} and Metabolism,

St Michael's Hospital,

University of Toronto

Gerald S Wong, MD, assistant professor

Robert G Josse, $\mathrm{MD}$, associate professor

Correspondence to:

Dr Jenkins, Division of

Endocrinology and

Metabolism, St Michael's

Hospital, Toronto,

M5B IW8. research associate

Silvia Guidici, RPDT research

\section{Abstract}

Study objective-To determine the effect on the glycaemic response to bread of the ratio of whole cereal grains to milled flour.

Design-Randomised assignment of groups of diabetic volunteers to test and control meals, taken after an overnight fast. Test foods were also analysed for in vitro digestion with human saliva.

Setting-Tertiary care centre.

Patients-Groups of six drawn from pool of 16 volunteers with diabetes mellitus $(11$ men, five women; mean age 64 (SE 3); 10 taking insulin, five taking oral agents, one controlled by diet; other characteristics comparable).

Interventions-All patients took standard white bread control meals on three occasions spanning the study and on different mornings took test meals containing varying ratios of whole cereal grains (barley or cracked wheat) to milled flour (75:25, $50: 50,0: 100)$. All meals contained $50 \mathrm{~g}$ available carbohydrate and were eaten in $\mathbf{1 5}$ minutes. Capillary blood samples were taken for determination of glucose concentrations every $\mathbf{3 0}$ minutes for three hours.

End point-Glycaemic index of foods (=increase in area under blood glucose concentration curve for test food $\div$ increase in area under curve for white bread control $\times 100$ ).

Measurements and main results-Significant trend to lower glycaemic index with increasing proportion of whole cereal grains in test bread $(\mathbf{p}<0.05)$ and with lower in vitro digestibility $(\mathbf{p}<0.001)$. Breads containing up to $75 \%$ whole grain were considered palatable.

Conclusions-Breads containing a high proportion of whole cereal grains may be useful in reducing the postprandial blood glucose profile in diabetics because they are more slowly digested. These breads should be called "wholegrain" in distinction to "wholemeal" breads made from milled flour.

\section{Introduction}

The term "wholegrain" (whole wheat, whole rye, etc) seems inadequate as currently used for cereal products. It is applied equally to cereal products such

TABLE I-Details of diabetic patients taking test meals

\begin{tabular}{|c|c|c|c|c|c|c|c|}
\hline \multirow{2}{*}{$\begin{array}{c}\text { Case } \\
\text { No }\end{array}$} & \multirow[b]{2}{*}{ Sex } & \multirow{2}{*}{$\begin{array}{c}\text { Age } \\
\text { (years) }\end{array}$} & \multirow{2}{*}{$\begin{array}{c}\% \\
\text { Ideal } \\
\text { weight }\end{array}$} & \multirow{2}{*}{$\begin{array}{c}\text { Duration of } \\
\text { diabetes } \\
\text { (years) }\end{array}$} & \multicolumn{2}{|c|}{ C peptide (ng/l) } & \multirow[b]{2}{*}{ Treatment } \\
\hline & & & & & Fasting & At 90 minutes & \\
\hline 1 & M & 62 & 102 & 5 & 1.40 & $4 \cdot 50$ & Glibenclamide $10 \mathrm{mg}$ twice daily \\
\hline 2 & $M$ & 57 & 153 & 6 & $2 \cdot 50$ & $7 \cdot 00$ & Glibenclamide $5 \mathrm{mg}$ twice daily \\
\hline 3 & M & 78 & 110 & 7 & $10 \cdot 6$ & $16 \cdot 00$ & 5 Units insulin zinc suspension \\
\hline 4 & $M$ & 42 & 129 & 6 & $3 \cdot 40$ & $6 \cdot 60$ & Glibenclamide $5 \mathrm{mg}$ thrice daily \\
\hline 5 & $\mathbf{M}$ & 74 & 124 & 5 & $3 \cdot 65$ & $9 \cdot 80$ & Diet only \\
\hline 6 & $M$ & 70 & 114 & 2 & 1.08 & 1.56 & Glibenclamide $10 \mathrm{mg} \mathrm{am}, 5 \mathrm{mg} \mathrm{pm}$ \\
\hline 7 & $M$ & 70 & 96 & 20 & 0.94 & $1 \cdot 72$ & 32 Units insulin zinc suspension \\
\hline 8 & $M$ & 76 & 108 & 24 & 1.00 & $2 \cdot 60$ & 20 Units insulin zinc suspension \\
\hline 9 & $\mathrm{~F}$ & 31 & 100 & 2 & 1.08 & 1.63 & 34 Units insulin zinc suspension \\
\hline 10 & $\mathrm{~F}$ & 69 & 126 & 28 & $2 \cdot 40$ & $5 \cdot 20$ & 34 Units insulin zinc suspension \\
\hline 11 & M & 69 & 114 & 15 & $11 \cdot 5$ & $13 \cdot 00$ & 50 Units insulin zinc suspension \\
\hline 12 & $\mathrm{~F}$ & 65 & 104 & 10 & 0.94 & $1 \cdot 12$ & 24 Units insulin zinc suspension \\
\hline 13 & $\mathbf{F}$ & 63 & 119 & 9 & $2 \cdot 02$ & $3 \cdot 45$ & 68 Units insulin zinc suspension \\
\hline 14 & $M$ & 68 & 109 & 15 & $3 \cdot 75$ & $5 \cdot 30$ & 24 Units insulin zinc suspension \\
\hline 15 & $\mathrm{~F}$ & 64 & 118 & 4 & 1.55 & $4 \cdot 60$ & 20 Units insulin zinc suspension \\
\hline 16 & $M$ & 71 & 108 & 10 & 1.92 & 3.77 & Glibenclamide $10 \mathrm{mg}$ twice daily \\
\hline Mean & & $64 \cdot 3$ & $114 \cdot 6$ & $10 \cdot 5$ & $3 \cdot 11$ & $5 \cdot 49$ & $31 \cdot 1$ \\
\hline SE & & $3 \cdot 1$ & $3 \cdot 5$ & $2 \cdot 0$ & $0 \cdot 81$ & $1 \cdot 06$ & $5 \cdot 5$ \\
\hline
\end{tabular}

as pumpernickel bread, in which a large proportion of the whole cereal grain remains intact, and to highly milled products such as wholemeal bread, in which the flour contains all of the original dietary fibre but none of the original form of the food. The importance of this issue is exemplified by the advice given to patients with diabetes to increase their consumption of wholegrain products: the terms wholegrain and wholemeal are used synonymously. ${ }^{12}$ Nevertheless, there seem to be major differences in the physiological response to wholegrain as opposed to wholemeal foods. Particle size is now recognised as an important determinant of the glycaemic response to cereals such as rice, wheat, rye, and maize. ${ }^{3.5}$ Blood glucose concentrations increase less when pumpernickel rye bread containing whole grain is eaten than when bread made with a milled rye flour is eaten. ${ }^{+}$

We studied the effect on the glycaemic response of increasing the proportion of whole barley grains or coarse cracked wheat in breads made from the milled flours of these cereals. We wanted to determine whether a linear response existed between the proportion of whole grains or coarse particles and the glycaemic response and whether the currently accepted nomenclature for products containing wholegrain cereals needed revision.

\section{Methods}

Volunteers drawn from a pool of 16 diabetics positive for $\mathrm{C}$ peptide were studied (table I). The 11 men and five women had a mean age of 64 (SE 3) and weighed $115(4) \%$ of their ideal weight. ${ }^{6}$ Ten had their diabetes controlled with insulin, five with oral agents, and one with diet alone. They took two or more of the test foods in random order on separate mornings after overnight fasts; six to eight subjects took each test food. All patients also took a control meal of white bread ( $50 \mathrm{~g}$ carbohydrate) on three separate occasions during the test period. All meals contained $50 \mathrm{~g}$ available carbohydrate (estimated from food tables ${ }^{7}$ ) and consisted of barley kernels alone or of bread containing whole barley and barley flour in the ratios $75: 25,50: 50$, and $0: 100$, or of bulgur alone or of breads containing cracked wheat in the same ratios.

Ten minutes before each meal patients took their usual dose of insulin or oral hypoglycaemic agent. They attempted to eat each meal within 10 minutes. The grains or bread were taken with two cups of tea or coffee $(400 \mathrm{ml})$ containing a total of $60 \mathrm{ml}$ of $2 \%$ butterfat milk. Subjects recorded palatability and satiety on bipolar semantic scales: at the end of each meal they gave it a palatability score of -3 to $+3(-3$ being highly disliked and +3 highly delectable), and satiety was scored at $0,30,90$, and 180 minutes after the start of the meal from -3 (very hungry) to +3 (very full). Capillary blood samples were taken by finger pricks just before the meal and at half hour intervals for three hours thereafter and were analysed by a glucose oxidase method. ${ }^{8}$ The glycaemic response (the blood glucose profile with the fasting value as the baseline) was plotted for each meal tested by each subject, and the area under the curve was determined. The glycaemic index was calculated':

Glycaemic index $=$ Area under the curve for test food $\times 100$ Area under the curve for white bread 
In addition portions of the foods containing barley were digested in vitro by pooled human saliva in a dialysis system. ${ }^{10}$ Each portion contained $2 \mathrm{~g}$ carbohydrate, and five replications were carried out for each test food. The products of carbohydrate digestion were sampled at hourly intervals over three hours and analysed by high performance liquid chromatography. ${ }^{10}$

The significance of differences between foods in each series was assessed by analysis of variance. ${ }^{11}$ The regression equations were calculated for the relation of the proportion of whole grain in the meal to the glycaemic index and for the rate of digestion in vitro to the corresponding glycaemic index.

\section{Results}

All the meals were eaten within 15 minutes and did not differ significantly from meals containing white bread in terms of palatability, eating time, or satiety with the exception of the 50:50 barley bread, which took 3.0 (SE 1.1) minutes longer to eat than white bread $(\mathrm{p}<0.05)$.

The glycaemic responses to the meals of barley and bulgur breads and grains decreased when a higher proportion of whole grains of cereal were present (table II). The breads made from 100\% wholemeal flour (wheat or barley) resulted in glycaemic responses that were not significantly different from those for white bread. As the proportion of whole or cracked grains in bread increased the glycaemic response decreased. This tendency was significant for both barley $(p<0.05)$ and bulgur $(p<0.05)$ (fig 1$)$. Table III gives the results of the in vitro tests on the foods containing barley. The glycaemic indices of the test

TABLE III - In vitro digestion of barley, breads containing barley, and white bread. Numbers are mean (SE) concentrations of total sugars (glucose, maltose, and maltotriose) in dialysis fluid after three hours

ring same uperscript are significantly different $(p<0 \cdot 05)$.

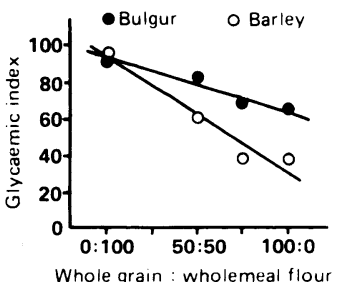

FIG 1-Glycaemic index for barley and bulgur related to proportion of whole grain in flour used for bread. For barley, glycaemic index $=94-0.61 \times$ percentage of whole grain; SEM of slope $=0.11 ; p<0.05$. For bulgur, glycaemic index $=$ 93-0.28 $\times$ percentage of whol grain; $S E M$ of slope $=0.049$; $p<0.05$

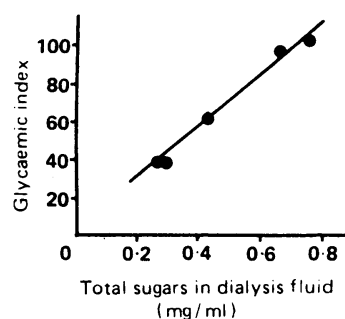

FIG 2-Glycaemic index for barley related to concentration of total sugars in dialysis fluid at three hours. Glycaemic index= $132 \times$ total sugars in dialysis fluid $+3 \cdot 6 ;$ SEM of slope $=9 \cdot 63$; $p<0.001$. vitro digestibility expressed as the concentration of total sugars in the dialysis fluid at three hours $(\mathrm{p}<0.001)$ (fig 2).

Of the foods containing barley, the bread with $50 \%$ whole grain resulted in a significantly lower mean glycaemic index than wholemeal barley bread, and both the $75 \%$ wholegrain barley bread and the meal of $100 \%$ wholegrain barley resulted in lower glycaemic indices than the $50 \%$ wholegrain bread. Of the foods containing bulgur, the $75 \%$ bulgur bread resulted in a mean glycaemic index significantly below that for wholemeal bread, and the meal including $100 \%$ bulgur resulted in a lower mean glycaemic index than either the wholemeal bread or the bread made with $50 \%$ bulgur.

\section{Discussion}

The glycaemic response decreased when whole or cracked cereal grains were substituted for milled flour in bread. The reduction was greater with breads containing higher proportions of whole grains. This advantage over flours milled from whole grains highlights the inadequacy of the term "wholegrain," which may refer to foods containing the intact grain or those that contain appropriate proportions of all the milled constituents (bran, endosperm, germ) of the grain. It therefore seems important for at least two reasons to reserve the term wholegrain specifically for the intact or cracked kernel. Firstly, advice by diabetes associations has emphasised the nutritional advantages of wholegrain cereals, implying that they may result in lower postprandial blood glucose profiles than their non-wholegrain equivalents. ${ }^{12}$ Evidence in addition to the present study supports this when the term is interpreted literally.' The advantage of wholegrain cereals is not, however, obvious when wholegrain refers to the flour resulting from milling whole grains: no difference has been shown between breads or pasta made from wholegrain flour and from white flour. ${ }^{1213}$ Secondly, evidence of the benefits of cereal products containing intact or cracked grains may support the continued use of traditional products-for example, pumpernickel bread, barley soups, bulgur-and encourage the development of new wholegrain foods such as breads and muffins. We suggest that wholegrain should be used for products containing specified percentages of unmilled components (for example, $80 \%$ wholegrain, $50 \%$ wholegrain) and some other term, perhaps "wholemeal," should be used to indicate a milled flour product containing all the components of the whole grain.

Our results show the influence of the form of food on the glycaemic response. This has already been shown for rice (ground ${ }^{3}$ and parboiled ${ }^{14}$ ); bread and pasta ${ }^{121315}$; wheat ${ }^{4}$; rye kernels, pumpernickel, and wholemeal rye breads $^{4}$; coarse ground wheat, oats, and maize ${ }^{5}$, ground lentils ${ }^{1016}$; and whole and puréed apples and apple juice. ${ }^{17}$ The importance of particle size was shown by a study in which food was swallowed without chewing, which resulted in a flatter blood glucose response curve than did food chewed normally.$^{18}$ Food should not be eaten unchewed, but larger particles in foods may be advantageous.

Although cereal fibre in its disrupted form does not seem to be an important determinant of glycaemic response to cereals, the glycaemic indices for whole barley and barley breads are significantly lower than those for bulgur and cracked wheat breads. This may be due to the presence of the viscous $b$-glucan fibre in barley. Viscous soluble fibres rather than particulate insoluble fibres help reduce the postprandial rise in blood glucose concentration. ${ }^{19}$ This would also be expected with oats and oat bran, the other cereal rich in b-glucan fibre.

The size of rice particles has been shown to reduce

meals containing barley were closely related to their in
We thank our patients for their generous participation. The studies were funded by the Natural Sciences and Engineering Research Council, Canada. 
1 Special Report Committee. Guidelines for the nutritional management of diabetes mellitus: a special report from the Canadian Diabetes Association. 7 Can Dietetic Assoc 1981;42:110-8.

2 American Diabetes Association. Nutritional recommendations and principles for individuals with diabetes mellitus: 1986. Diabetes Care 1987;10:126-32.

3 O'Dea K, Nestel PJ, Antonoff L. Physical factors influencing postprandial glucose and insulin responses to starch Am f Clin Nutr 1980;33:760-5.

4 Jenkins DJA, Wolever TMS, Jenkins AL, et al. Low glycemic response to enkins DJA, Wolever TMS, Jenkins AL, et al. Low glycemic response to
traditionally processed wheat and rye products: bulgur and pumpernickel bread. Am f Clin Nutr 1986:43:516-20.

5 Heaton KW, Marcus SN, Emmett PM, Bolton CH. Effects of particle size on the plasma glucose and insulin responses to test meals of wheat, maize, and oats and on the rate of starch digestion in vitro. Am $\mathcal{f}$ Clin Nutr in press).

6 Diem K, Lentner C, eds. Documenta Geigy scientific tables. 7th ed. Basle: J R Geigy, 1970 .

7 Paul AA, Southgate DAT. McCance and Widdowson's the composition of foods. 4th ed. London: HMSO, 1978. (Medical Research Council special report No 297.)

8 Clark LC Jr. A polarographic enzyme electrode for the measurement of oxidase substrates. In: Kessler M, Bruley DF, Leland CC, Lubbers DW, Silver IA Strauss J, eds. Oxygen supply. Munich: Urban and Schwarzenberg, 1977: Strauss $120-8$.

9 Jenkins DJA, Wolever TMS, Jenkins AL, et al. The glycaemic index of foods tested in diabetic patients: a new basis for carbohydrate exchange favouring the use of legumes. Diabetologia 1983;24:257-64.

10 Jenkins DJA, Thorne MJ, Camelon $\mathrm{K}$, et al. Effect of processing on digestibility and the blood glucose response: a study of lentils. Am $\mathcal{F}$ Clin Nutr 1982;36:1093-101.

11 Snedecor GW, Cochran WG. Statistical methods. 7th ed. Ames, Iowa: Iowa State University Press, 1980

12 Jenkins DJA, Wolever TMS, Taylor RH, Barker HM, Fielden H, Gassull MA. Lack of effect of refining on the glycemic response to cereals. Diabetes Care 1981;4:509-13.
13 Jenkins DJA, Wolever TMS, Jenkins AL, Lee R, Wong GS, Josse R. Glycemic response to wheat products: reduced response to pasta but no effect of fibre. Diabetes Care 1983;6:155-9.

14 Wolever TMS, Jenkins DJA, Kalmusky J, et al. Comparison of regular and parboiled rices: explanation of discrepancies between reported glycemic parboiled rices: explanation of discrepancies betweer

15 Parillo M, Giacco R, Riccardi G, Pacioni C, Rivellese A. Different glycaemic responses to pasta, bread, and potatoes in diabetic patients. Diabetic Med responses to
$1985 ; 2: 374-7$.

16 Wong S, O'Dea K. Importance of physical form rather than viscosity in determining the rate of starch hydrolysis in legumes. Am f Clin Nutr 1983;37:66-70.

17 Haber GB, Heaton KW, Murphy D, Burroughs LF. Depletion and disruption of dietary fibre: effects on satiety, plasma-glucose, and insulin. Lancet 1977;ii:679-82.

18 Read NW, Welch IMcL, Austen CJ, et al. Swallowing food without chewing: a simple way to reduce postprandial glycaemia. $\mathrm{Br} \mathcal{F} \mathrm{Nutr}$ 1986;55:43-7.

19 Jenkins DJA, Wolever TMS, Leeds AR, et al. Dietary fibres, fibre analogues, and glucose tolerance: importance of viscosity. Br Med f 1978;i:1392-4.

20 Torsdotrir I, Alpsten M Andersson D, Brummer RJM, Andersson $H$. Effect of different starchy foods in composite meals on gastric emptying rate and . Cote and glucose metabolism. I. Comparisons between

21 Brand JC, Nicholson PL, Thorburn AW, Truswell AS. Food processing and the glycemic index. Am 7 Clin Nutr 1985;42:1192-6.

22 O'Dea K, Snow P, Nestel P. Rate of starch hydrolysis in vitro as a predictor of mea K, Snow P, Nestel P. Rate of starch hydrolysis in vitro as a predictor of
metabolic responses to complex carbohydrate in vivo. Am $\mathcal{J}$ Clin Nutr 1981;34:1991-3.

23 Simpson HRC, Simpson RW, Louslely S, et al. A high carbohydrate leguminous fibre diet improves all aspects of diabetic control. Lancet 1981;i:1-5.

(Accepted 20 May 1988

\title{
Relation of serum calcium concentration to metabolic risk factors for cardiovascular disease
}

\author{
Lars Lind, Sören Jakobsson, Hans Lithell, Bo Wengle, Sverker Ljunghall
}

\begin{abstract}
Data from a health screening survey with over 18000 adult participants were used to determine the relations between serum calcium concentration and the cardiovascular risk factors hypertension, hyperglycaemia, and hyperlipidaemia. Blood pressure and serum glucose and cholesterol concentrations were all positively related to each other independent of age, sex, kidney function, and obesity. Similar relations between the risk factors were found in subjects with hypertension or hyperglycaemia independent of the degree of overweight. These results suggested that there might be a metabolic syndrome of cardiovascular risk factors. Serum calcium concentration was positively related to systolic and diastolic blood pressures and serum glucose and cholesterol concentrations. Thus a common feature in the syndrome is an increased serum calcium concentration. The relations between serum calcium concentrations and the cardiovascular risk factors were not limited to the upper parts of the distribution, being seen over a wide range.
\end{abstract}

Changes in calcium metabolism seem to be related to a metabolic syndrome of hypertension, impaired glucose tolerance, and hyperlipidaemia.

\section{Introduction}

The calcium ion is an essential regulator in many homoeostatic systems, including vascular tone, hormone secretion, and intermediary metabolism.' Calcium metabolism is reportedly altered in both hypertension $^{2}$ and diabetes mellitus, ${ }^{3}$ and a pathogenetic role for calcium in the aetiology of hypertension has been suggested. ${ }^{4}$ Hypertension, hyperglycaemia, and hyperlipidaemia are all well known risk factors for the development of cardiovascular disease, ,-7 $^{5-7}$ and their coexistence might therefore be particularly important. We investigated interrelations between these risk factors and their relations to serum calcium concentration using data from a large health screening survey.

\section{Subjects and methods}

During 1969-70 all 24171 inhabitants aged over 25 in a central district of Gävle, Sweden, were invited to participate in a health screening survey; $77 \%$ of the invited population took part (8416 men and 10127 women). The non-participants were mainly from the youngest (25-35) and oldest (>85) age groups. The studied sample was considered to be representative for the ages 35-85 and large enough for us to study interrelations between metabolic variables. The aims of the health screening were to find undetected diseases and to evaluate the effects of such screening. The participants were asked to attend according to home address rather than by age or sex.

A venous blood sample was taken, usually in the afternoon after four hours of fasting, and analysed with a Technicon autoanalyser SMAC 12/60 (Mark Technicon Corp, USA) for serum glucose, cholesterol, calcium, and albumin concentrations and blood urea nitrogen concentration. Particular attempts were made to eliminate sources of error in the measurements. The results were compared with those obtained from standard samples (every fifth to 10th sample) from a large pool of serum calibrated every second week against a commercial reference. The serum calcium concentrations in the study were all adjusted for the serum albumin concentration according to the formula: calcium (adjusted) $=$ calcium (analysed) 0.0077 (albumin-43.3), where 0.0077 was the determination coefficient of the regression analysis and 43.3 the mean albumin concentration in the population. ${ }^{8}$

Body mass index, used as an index of obesity, was defined as weight $(\mathrm{kg}) /$ height $(\mathrm{m})^{2}$. Blood pressure was measured in the supine position after 10 minutes' rest
Correspondence to:

Dr Ljunghall. 